\title{
Reproductive health needs of married girls in Assuit and Sohag Governorates [Arabic]
}

Population Council

Follow this and additional works at: https://knowledgecommons.popcouncil.org/departments_sbsr-pgy

Part of the Family, Life Course, and Society Commons, Gender and Sexuality Commons, International Public Health Commons, Maternal and Child Health Commons, and the Women's Health Commons How does access to this work benefit you? Let us know!

\section{Recommended Citation}

"Reproductive health needs of married girls in Assuit and Sohag Governorates [in Arabic]," Policy brief. Cairo: Population Council, 2015. 


\section{نظرة على احتياجات الصحة الإنجايية

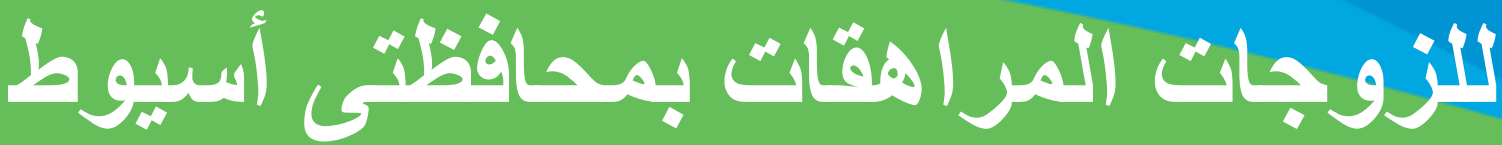

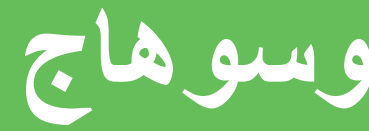

\section{لماذا الاهتمام بدراسة الزوجات المراهقات؟}

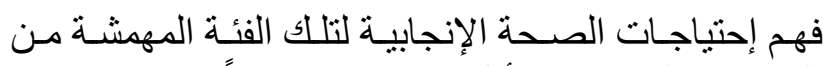

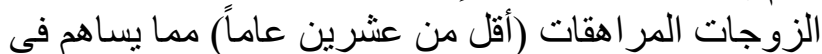

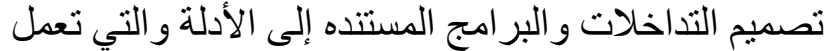

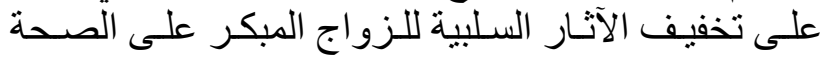

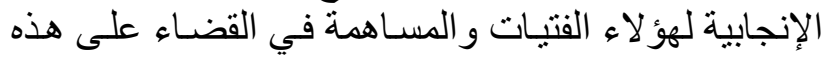

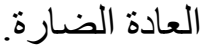

وتعـد هذه الدر اسـة أحد مكونـات المبـادرة التي يقوم بهـا

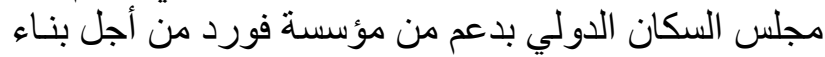
كو ادر بحثية في مجال الصحة الإنجان مؤنية للثنباب.
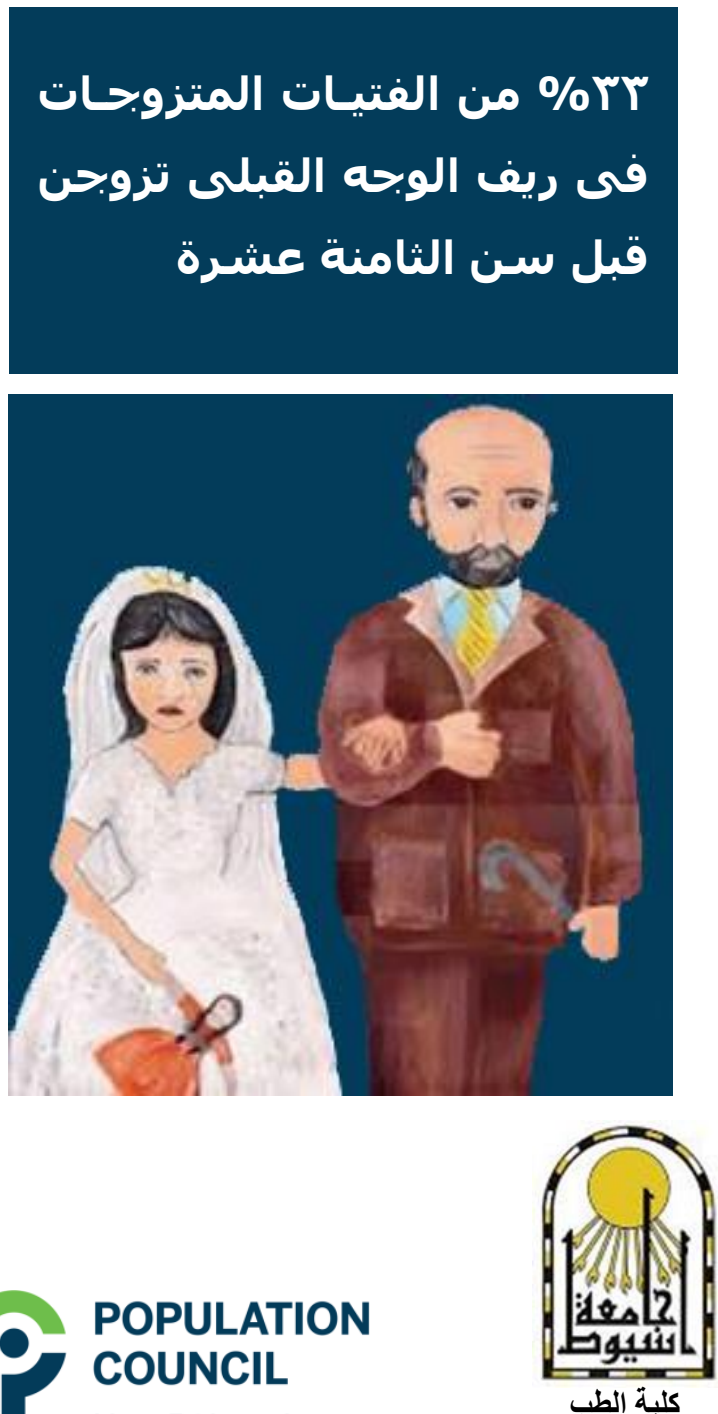

قسم الصحة العامة

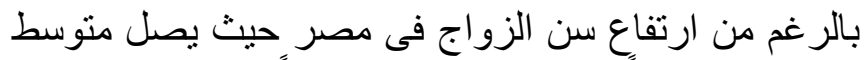

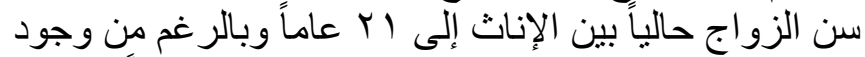

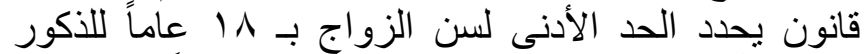

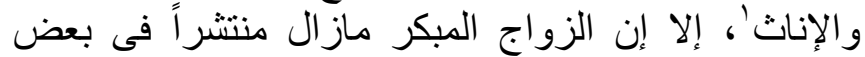

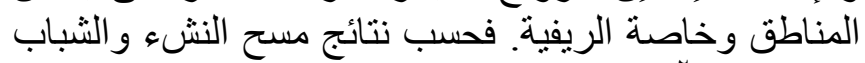

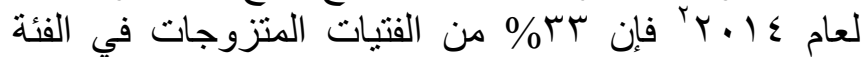

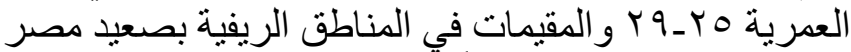

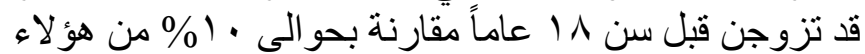

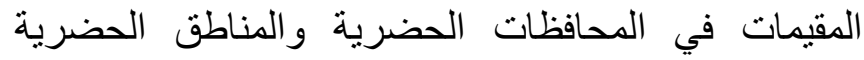

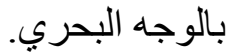

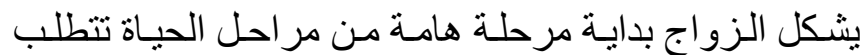

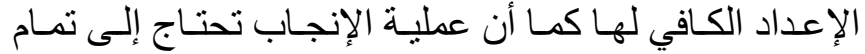

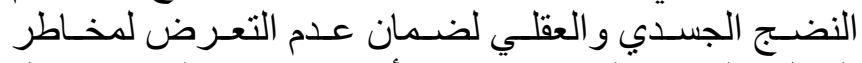

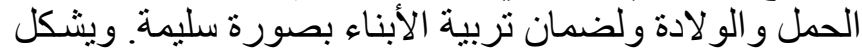

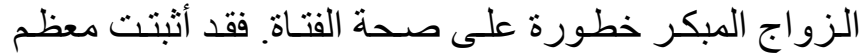

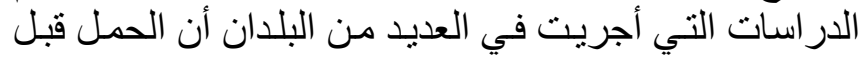

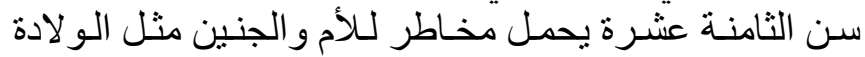

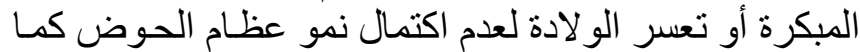

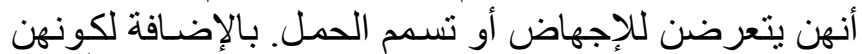

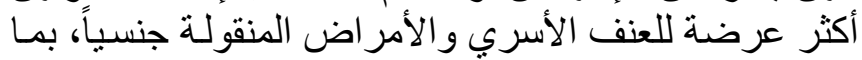

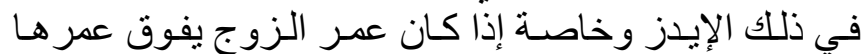

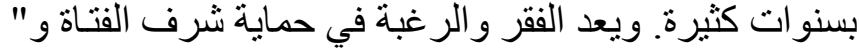
سترتها " من أهم أسباب انتشار الزواج الفئر المبكر.

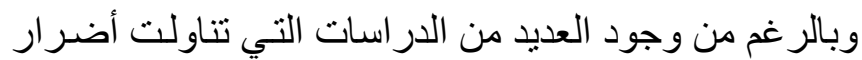

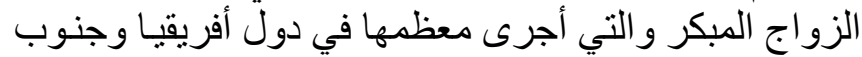

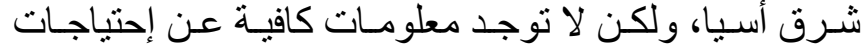

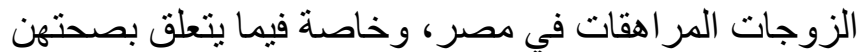

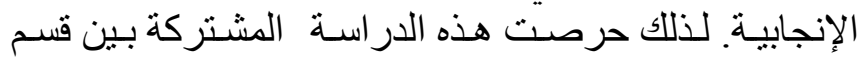

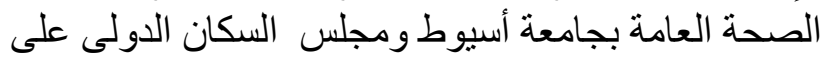

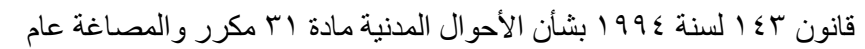

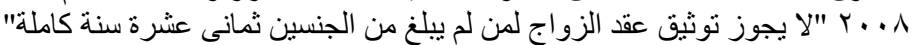

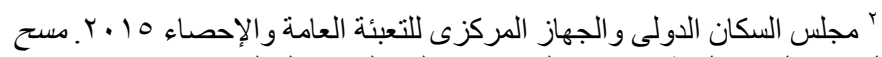

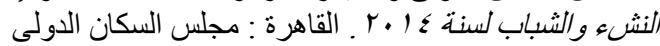

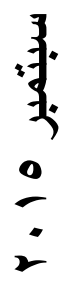




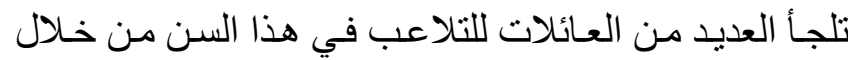

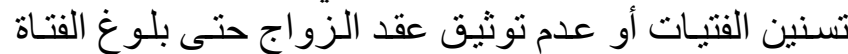

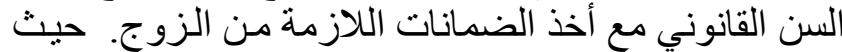

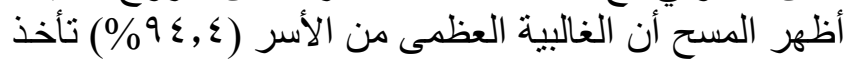

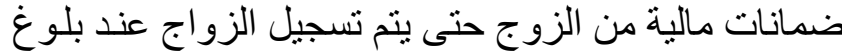
الفتاة السن القانونى للزواج التزو

\section{السلوك الإنجابي والمعرفة عن الصحة}

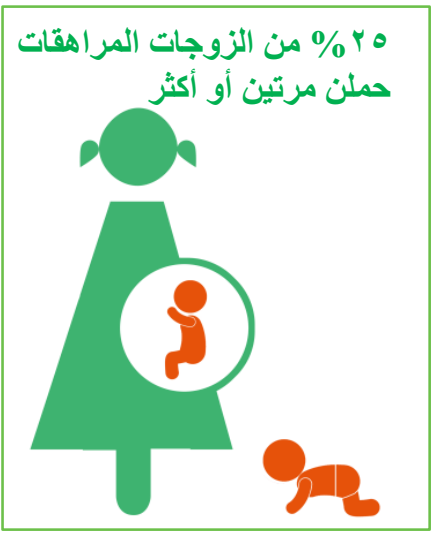

أظهرت الدراسة أن معظم

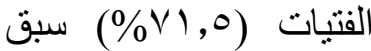

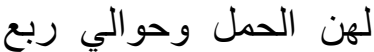
العينة حملن مرتين أو أو أكثر وكانت منوسط مدة مدة

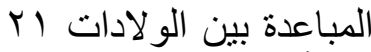

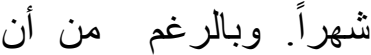
نسبة متابعة الحمل عالية بين المبحوثات اللاتي سبق لهن الحمل (†^^\% في الحمل

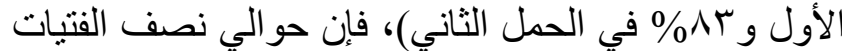

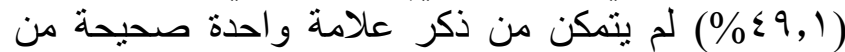

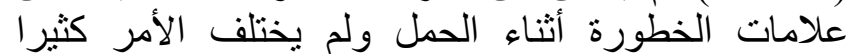

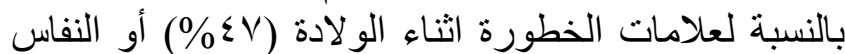

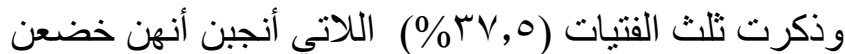

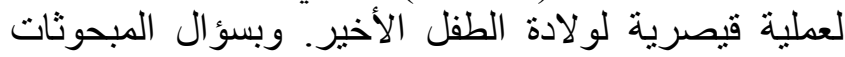

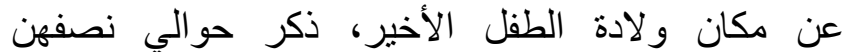

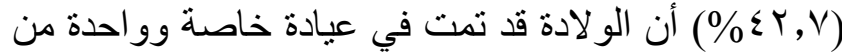

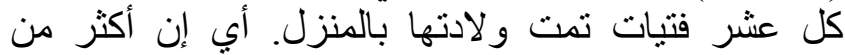

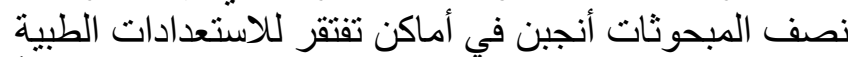
اللازمة مع كون هؤلاء الزوجات المات المرات اهقات أكثر تعرضاً

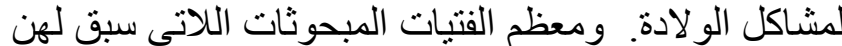

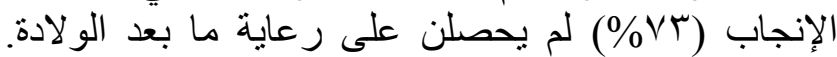

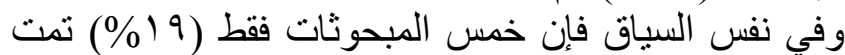
زيارتهن منزلياً بعد الزواج من قبل فريق العمل بالوحدة

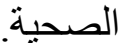

وبالرغم من أن معظم المبحوثات ذكرن أنهن عانين من الإن الإنهات

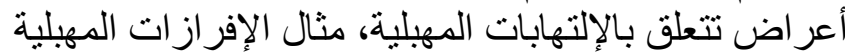

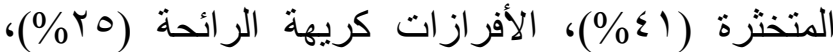

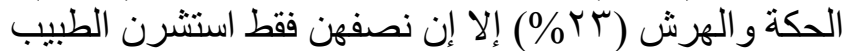

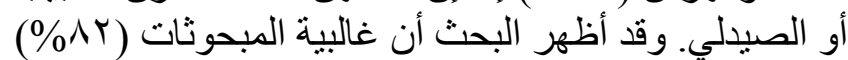

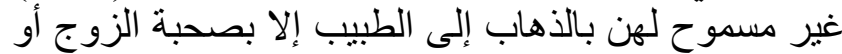

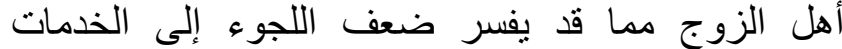
الصحية في حالة المشكلات الصحية المتعلقة بالإلتهابات الإت التهات
دراسة الزوجات المراهقات في محافظتي أسيوط وسو هاج التروجات

أجريت هذه الدر اسة بمحافظتى أسيوط وسوهاج خلال الفترة من

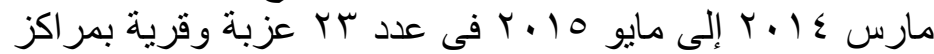

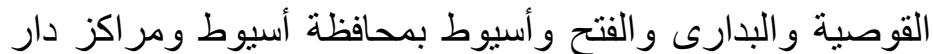

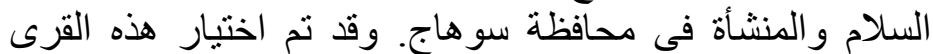

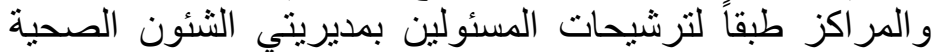

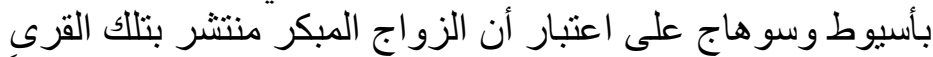

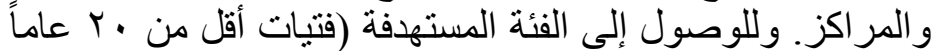

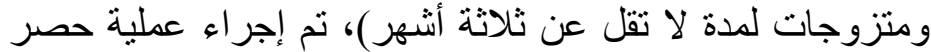
وترقيم للمنازل فى العزب و القرى المختارة بو اسطة فرئ فريق مدرب

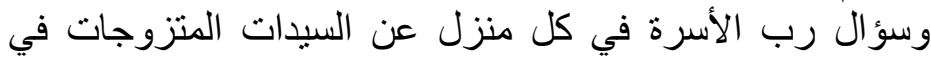

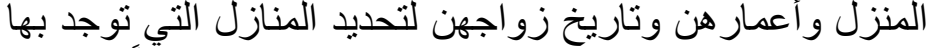
فتاة أو أكثر في الفئة المستهدفة و إجر اءون مقابلة معهن لاحقاً.

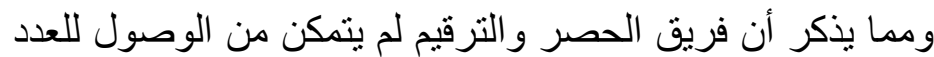
المستهدف، وقد يكون ذلك بسبب إنكار الأهالي لوجود فنيات الوديات متزوجات تحت السن القانوني لخوفهم من المساءلة القانونية أو لوات

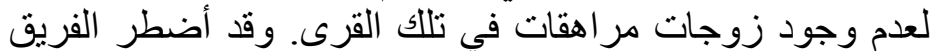

البحثي إلى التوسع زللقرى و العزب المحيطة بالأماكن المختارة.

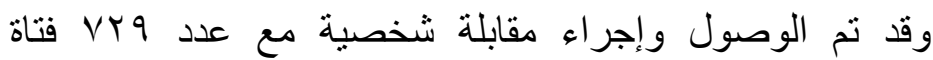

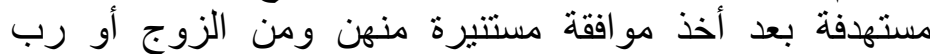
الأسرة. وخلال المقابلة الثخصية تمت مناقثنة الجوانب التباتة الحياتية

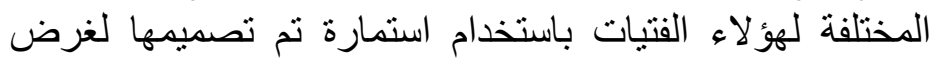

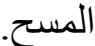

\section{سـبعة مـن كل عشـر فتيـات لـم يـتم توثيـق \\ زواجرهن فـى حينه حيـث تـزوجن وهـن لـم يبلغن الثامنة عشرة من العمر. \\ مواصفات الزوجات المراهقات}

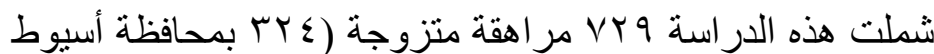

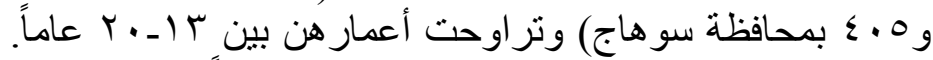
وكان متوسط عمر الفتيات عند الزواج

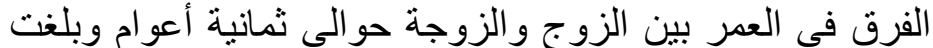

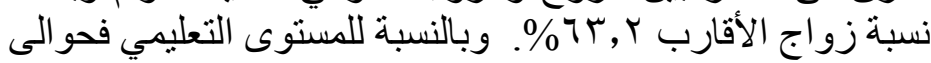

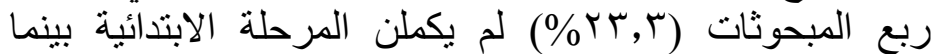

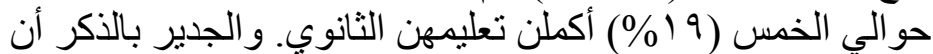

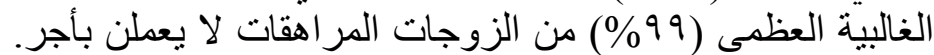

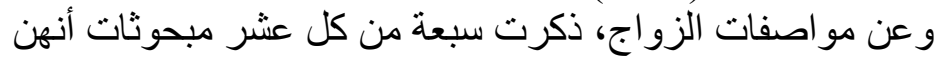

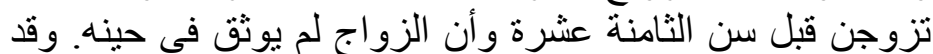

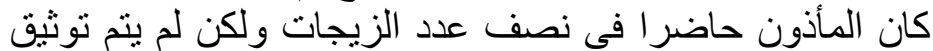

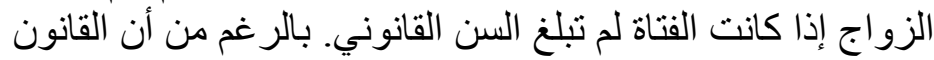

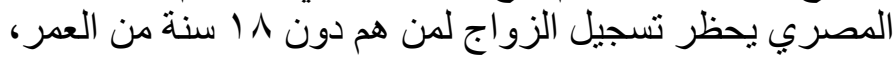




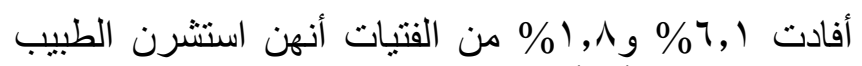
في حالة وجود ألم أثناء الجماع وفي حالة عدم وجود رغبة الفية جنسية على التوالي.

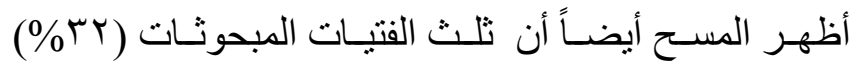

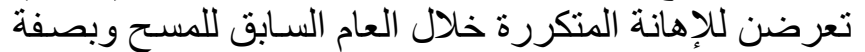

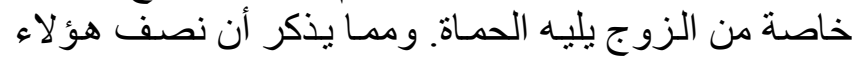

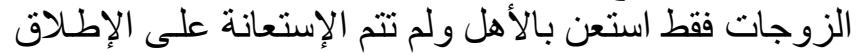

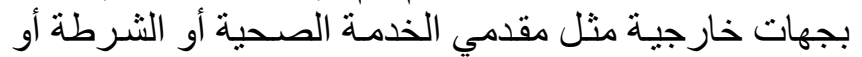

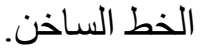

\section{الخلاصة والتوصيات}

مما سبق يتضح لنا أن الزوجات المر اهقات يتعرضن للكثير من المخاطر الصحية نتيجة لنقص المعلو لنقات التصات المتاحة لهن فيما يتعلق بصحتهن الإنجابية. فهن يتعرضن لفرية لمخاطر الحمل المبكر والمتكرر نتيجة لعدم إستخدامهن لوسائل فئل تنظيم الإني الأسرة ولرغبتهن في إنجاب عدد كبير من الأطفال.

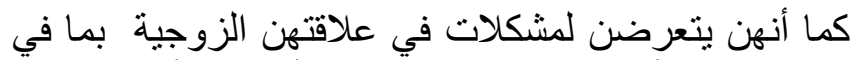

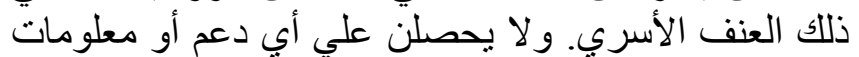

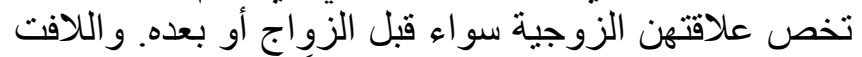

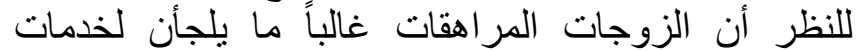

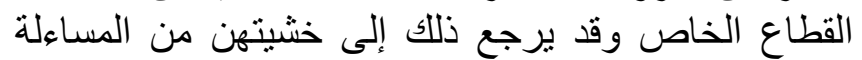
القانونية لصغر سنهن.

إن تلبية إحتياجات الصحة الإنجابية للزوجات المراهقات

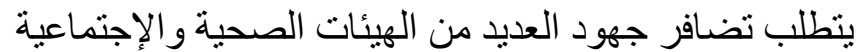

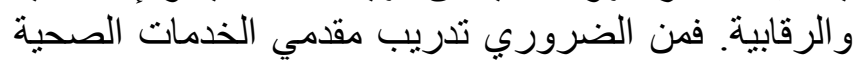
بالوحدات الصحية الأولية ومر اكز طب الإبة الأسرة التي تقدم رعاية ما قبل الزواج علي إحتياجات الصحة الإلية الإنجابية للمر اهقات المتزوجات بما في ذلك المئ المشورة الخاصة بالعلاقة الإنة

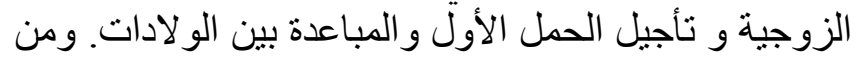

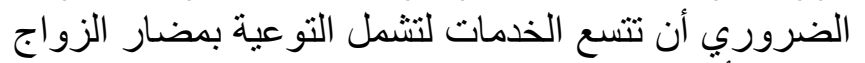
المبكر و ألا يشترط سن معينة للحصول علي تللك الخدمات.

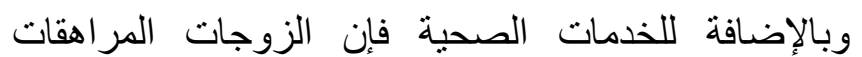
يحتجن إلي برامج تثقيفية وتدريبية لتأهيلهن وإنهان وإكسابهن

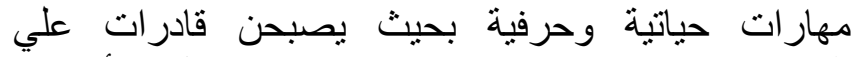

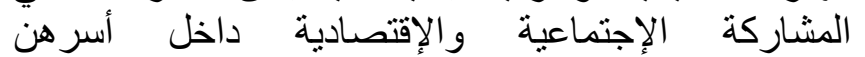

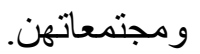
أخيراً وليس آخراً، إن الإرتقاء بصحة الزونات الزوات المرات اهقات

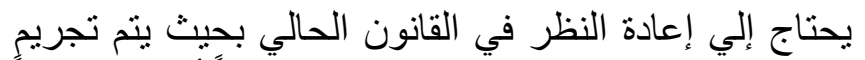

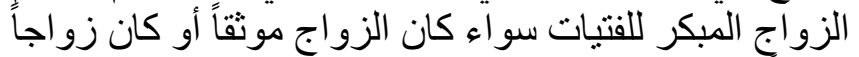

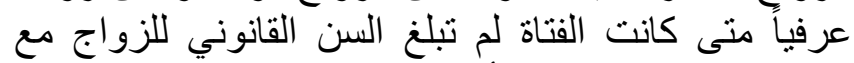

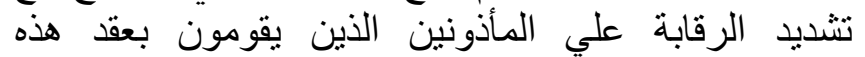

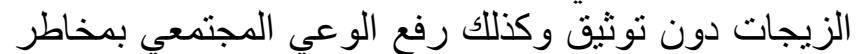

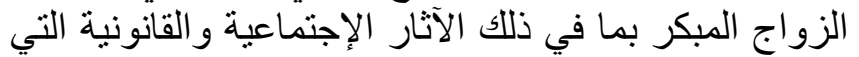
تنتج عن عدم توثيق الزوراج.

\section{حوالى ا | \% فقط من الفتيـات قـد سـبق \\ لرهن استخدام وسائل تنظيم الأسرة}

غالبيـة الفتيـات المتزوجـات كن على معرفـة بوسـائل تتظيم

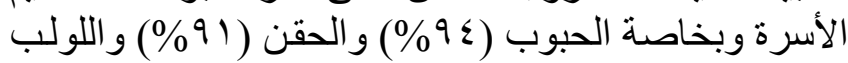

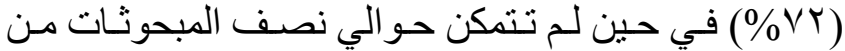
معرفة الثروط اللازمة لإستخدام الرضاعة الطبيعة الطية كوسيلة

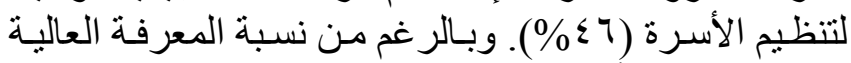

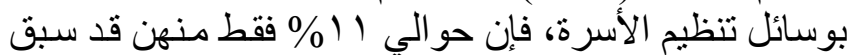

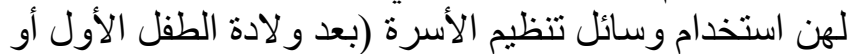

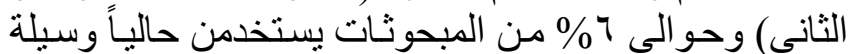

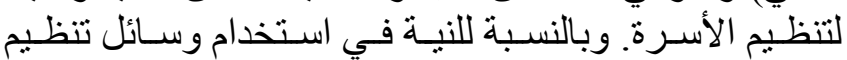

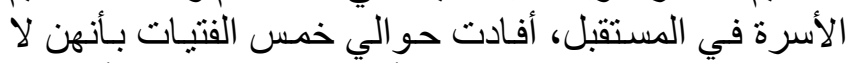
يعتزمن استخدام وسائل تنظيم الأسرة في المستقبل وألفيل وأرجعن

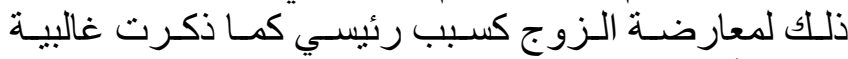

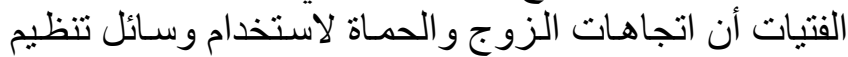

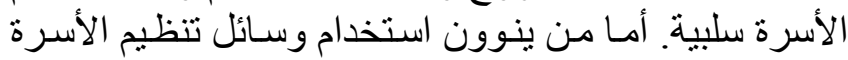

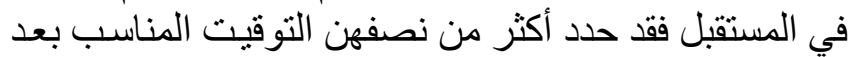

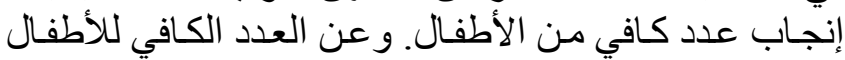

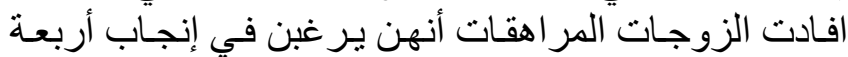

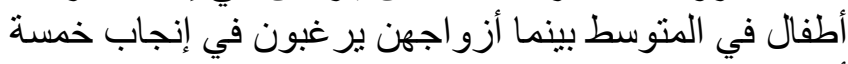

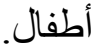

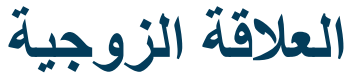
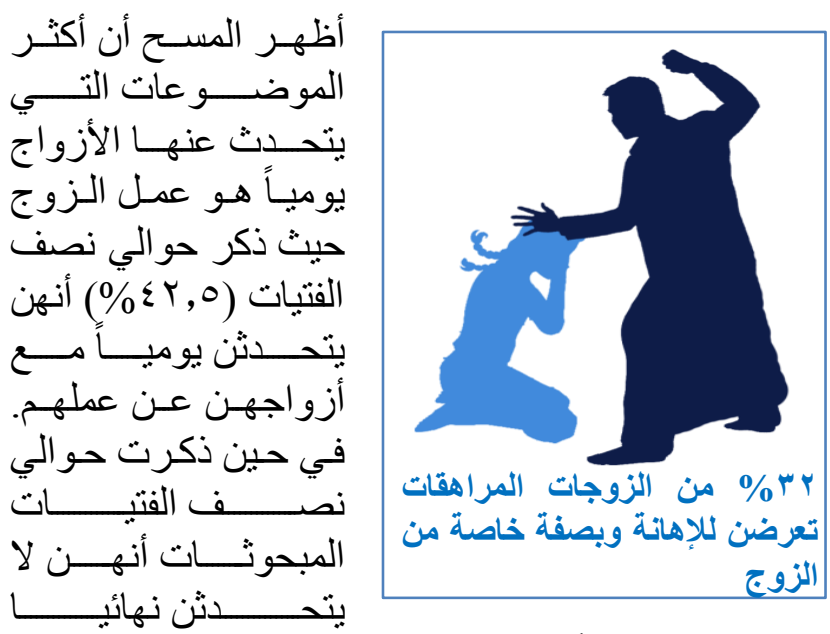

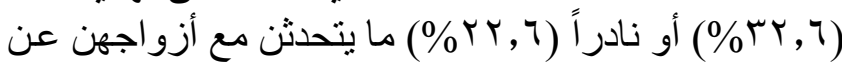

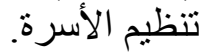

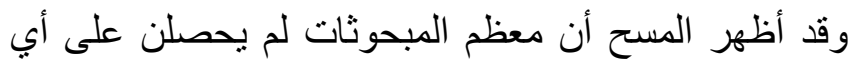

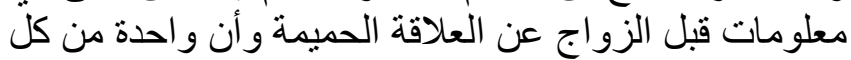
عثر مبحوثات غير راضية عن العلاقة الحميمة مع الزونة الزون.

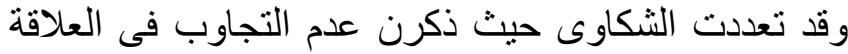

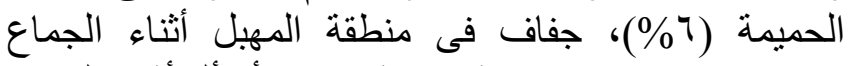

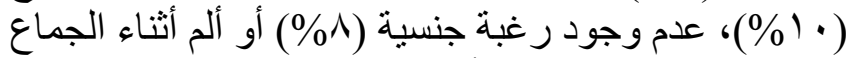

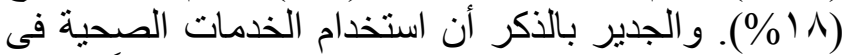
حالة وجود مشكلات صحية جنسية يكاد يكون منعدماً، حيث الثي الثي 


\section{شيكر وتثمبر}

يتثلم فريق العمل بمجلس السكان الدولي وقشم الصحة العامـة بجامعة أسيوط بخالص

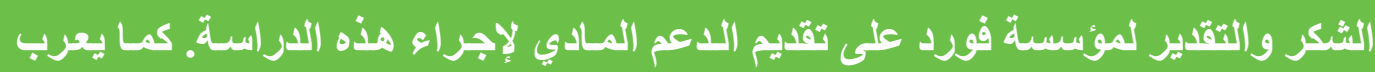

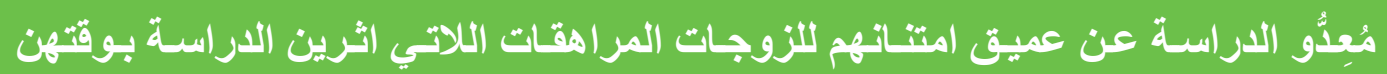

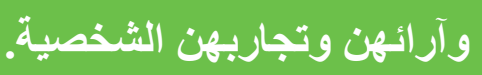

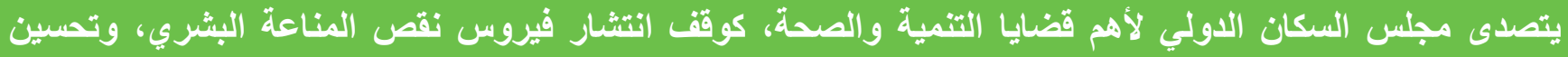

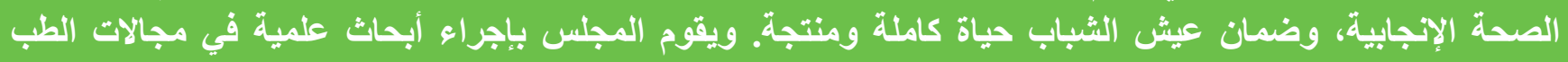

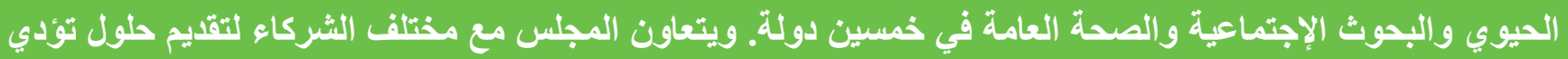

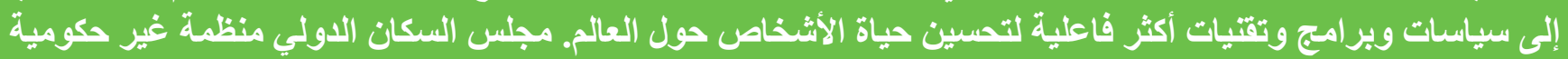

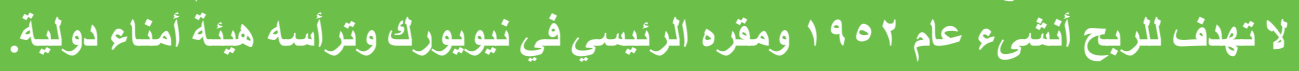

Population Council One Dag Hammarskjold Plaza New York, NY 10017

$$
\begin{aligned}
& \text { مجنس السكان الدولي - مصر }
\end{aligned}
$$

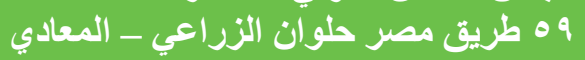

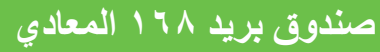

$$
\begin{aligned}
& \text { القاهزة - مصر بل } \\
& || \\
& \text { שاتف: }
\end{aligned}
$$

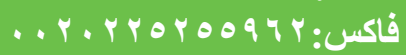

Info.egypt @ popcouncil.org:البريد الاكتروني الموقع الاكتروني: الاكتي: www.popcouncil.org

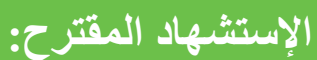

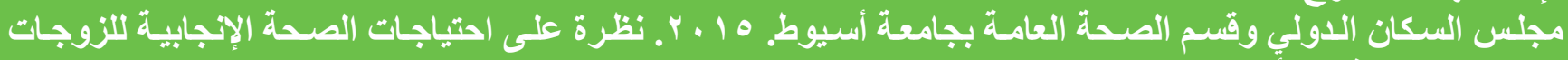

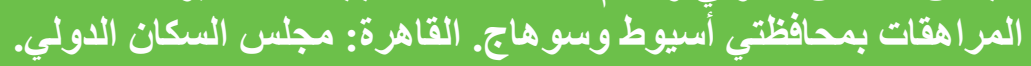

\section{POPULATION COUNCIL}

Ideas. Evidence. Impact. 